\title{
TERRITÓRIO E POLÍTICAS DE DESENVOLVIMENTO TERRITORIAL NO BRASIL: CONCEITOS, DESAFIOS E POSSIBILIDADES A PARTIR DA GOVERNANÇA
}

\author{
Territory and territorial development policies in Brazil: concepts, challenges and \\ possibilities from governance.
}

José Renato Ribeiro*

*Estudante Mestrado / UNESP Rio Claro - joserenatorbr@gmail.com.

Recebido em 08/04/2019. Aceito para publicação em 20/04/2019.

Versão online publicada em 26/04/2019 (http://seer.ufrgs.br/paraonde)

\begin{abstract}
Resumo: 0 presente artigo tem como objetivo expor alguns aspectos que permeiam a discussão sobre o desenvolvimento territorial, partindo de dois conceitos base, território e governança. Para tanto, buscamos problematizar a temática e citar algumas experiências nacionais como possiblidades de estudos futuros. A relevância de um trabalho como o apresentado se assenta na atualidade do debate sobre o desenvolvimento e que longe de manter o foco na dualidade Estado x mercado, podemos pensar em novas possibilidades, como o desenvolvimento territorial. As estratégias de desenvolvimento territorial, tendo como principio básico a existencia de modalidades de governança, tem surgido no Brasil como evidências de um novo modelo de gestão territorial e que tem se tornado objeto de estudos no campo das políticas públicas de desenvolvimento.
\end{abstract}

Palavras-chave: Território; Governança Territorial; Desenvolvimento Territorial.

\begin{abstract}
The present article has the objective of exposing some aspects that permeate the discussion about the territorial development, starting from two concepts base, territory and governance. To do so, we seek to problematize the theme and cite some national experiences as possibilities for future studies. The relevance of a paper like the one presented is based on the current debate on development and that, far from maintaining the focus on the duality of the state $\mathrm{x}$ market, we can think of new possibilities, such as territorial development. Territorial development strategies, based on the existence of governance modalities, have emerged in Brazil as evidences of a new territorial management model and have become the object of studies in the field of public development policies.
\end{abstract}

Key-words: Territory; Territorial Governance; Territorial Development.

\section{Introdução}

A discussão sobre o desenvolvimento tem retornado à agenda pública da sociedade brasileira, especificamente sobre a problemática referente ao papel do Estado na economia. A questão circula no debate entre a adoção do intervencionismo ou do neoliberalismo, sendo que ambas apresentam a visão verticalizada (de cima para baixo) do processo de desenvolvimento.

Apesar dessas duas principais tendências ou concepções majoritárias, podemos identificar uma possibilidade de pensar o desenvolvimento sustentado por uma possível complementariedade entre essas duas lógicas através da construção de ordenamentos institucionais (territoriais) intermediários entre o Estado e o mercado (BOYER, 1999). Esses ordenamentos podem assumir um papel relevante na formulação das políticas de desenvolvimento regional, buscando uma verdadeira inscrição territorial e valorização da participação social. São iniciativas específicas de desenvolvimento territorial caracterizadas por ações, estratégias e políticas destinadas a (re) construção da base produtiva local, podendo ou não, provocar impactos no território. Nesse sentido, a existência de dispositivos institucionais de cooperação e coordenação das ações é essencial, como 
as estruturas de governança territorial. Essas estratégias tem surgido no teritorio brasileiro evidenciando um novo modelo de gestão territorial e que tem se tornado objeto de estudos no campo das políticas públicas de desenvolvimento.

Com o apresentado, o objetivo desse trabalho é discutir alguns aspectos que permeiam a discussão sobre o desenvolvimento territorial, enfatizando a centralidade do território e da governança territorial. Para tanto, abordaremos brevemente três experiências brasileiras como as Câmaras Setoriais do Agronegócio, os Comitês de Bacias Hidrográficas e os Arranjos Produtivos Locais (APLS).

Este trabalho está organizado em cinco seções, sendo a primeira esta introdução. Na segunda será apresentada a definição e a problematização da noção de desenvolvimento territorial, bem como os conceitos que o sustentam (território e governança). Na terceira, serão expostos alguns esclarecimentos com base em criticas referentes à teoria do desenvolvimento territorial. Na quarta seção definiremos brevemente alguns dos exemplos mencionados anteriormente. Na quinta faremos as considerações finais.

\section{A dimensão territorial do desenvolvimento: a centralidade do território e da governança}

Diferentemente das perspectivas intervencionista (centralizada no Estado) e neoliberal (centrada no mercado) o desenvolvimento em sua dimensão territorial assinala a importância de se pensar a escala local como lugar efetivo de elaboração, mas não o único, de políticas de desenvolvimento. 0 desenvolvimento territorial não significa a manutenção do Estado da política keynesiana stricto sensu, de proteção e provedor do desenvolvimento (centralização das políticas dessa natureza) como querem os seus defensores, muito menos deixaria o mercado atuar sobre o território, como querem os neoliberais. Não se trata de pensar em um novo modelo de produção, mas sim, na emergência de novas formas de intervenção para o desenvolvimento, onde o Estado centralizador e a ação guiada pelo Mercado perdem importância relativa (MULS, 2008).

Importante, apontar que a concepção de desenvolvimento territorial está no campo do desenvolvimento regional/local, mas com aspectos que destoam fortemente dos planos de desenvolvimento centralizados no Estado e que sempre atenderam a uma política industrial, que na maioria das vezes desconhece ou ignora as características territoriais locais e a organização social de uma região. O desenvolvimento territorial (local, endógeno ou de baixo para cima), envolve a mobilização de atores, recursos e instituições com forte vínculo espacial, com objetivo de alavancar a competitividade das atividades econômicas locais e propiciar bem-estar social e cultural à comunidade que vive nesse meio (PECQUEUR, 2005; PIRES et al, 2011). A partir dessa breve definição, que vamos aprofundar adiante, apresentamos dois conceitos básicos para a compreensão do desenvolvimento territorial. São eles o território e governança (territorial).

O território, resultado de uma construção social determinada histórica e espacialmente, é permeado pela existência de identidade, contornos políticos, econômicos e sociais específicos, não devendo ser considerado como um produto estável ou imutável. Ao entender que o território apresenta uma dimensão material e imaterial-institucional, podemos entendê-lo como um espaço socialmente organizado, sendo dessa forma, um ator do desenvolvimento (BENKO, 2001; LLORENS, 2001; PIRES et al, 2006).

Esse protagonismo atribuído ao território permite que compreendamos a heterogeneidade e a complexidade do mundo real, além das particularidades e das territorialidades. Estes são elementos fundamentais para se pensar um processo de desenvolvimento local, uma vez que da as condições necessárias para que compreendamos os atores/agentes envolvidos, as políticas empregadas, as possibilidades, os desafios e os limites observados. Cabe reforçar a existência de características culturais e ambientais específicas, atores sociais atuantes e a mobilização em torno das diversas

ParaOnde!?, Porto Alegre, v.11, n.1, p.75-82, 2019. http://seer.ufrgs.br/paraonde

Edição Especial: “Geografia e transformações socioespaciais: dinâmicas agrárias e políticas do desenvolvimento regional” 
estratégias e projetos, assim como a disponibilidade a recursos estratégicos para o desenvolvimento econômico e social (PIRES et al, 2006). Nesse contexto territorial, consideramos central a observação sobre os mecanismos de cooperação e coordenação, no qual identificamos como modalidades de governança (territorial).

Sendo utilizado por diferentes ciências, como a Ciência Política, a Administração, a Economia e a Geografia, a noção de governança apresenta significados distintos. Não se trata de um conceito novo, sendo originalmente empregado em trabalhos sobre as formas operacionais utilizados para a coordenação de empresas ou firmas. Na década de 1980 é aplicado em trabalhos do Grupo Banco Mundial sobre a capacidade administrativa dos Estados, elaborando políticas, diretrizes e metas econômicas (e sociais) para os países subdesenvolvidos, ou seja, as recomendações neoliberais para os países pobres. Essa concepção neoliberal, ainda muito forte no âmbito político tem sido um dos obstáculos à aceitação de novas formas de se pensar a governança como tem feito Dallabrida (2011) que tem buscado ressignificar o conceito refutando a relativização do Estado, como querem os neoliberais e enfatizando uma perspectiva tripartite. É nesse contexto que a governança territorial é proposta e tem conseguido aceitação no campo acadêmico e político, sobretudo, devido ao processo de descentralização político-administrativo do Estado defendido pela Constituição Federal de 1988.

Para Dallabrida (2011, p. 01) a governança é um "conjunto de iniciativas ou ações que expressam à capacidade de uma sociedade organizada territorialmente para gerir os assuntos públicos a partir do envolvimento conjunto e cooperativo dos atores sociais, econômicos e institucionais", através das redes de poder socioterritoriais, que são representados por lideranças de cada um dos segmentos da sociedade organizada territorialmente. Nesse sentido o processo de desenvolvimento territorial trata-se de uma dinâmica onde se evidencia um conjunto de ações empreendidas por atores e ou agentes, organizações e instituições de uma sociedade determinada e identificada histórica e territorialmente.

Esses atores em seu conjunto integram o bloco socioterritorial e assumem a responsabilidade de promover a definição dos novos rumos do desenvolvimento do território, através de processo de concertação público-privada. Este processo de concertação se dá pela adoção de procedimentos voluntários de conciliação e mediação, no qual os diferentes representantes da rede de poder socioterritorial acabam assumindo uma prática de gestão territorial descentralizada. Essas redes de poder, como já mencionado, são compostas por lideranças de cada um dos segmentos que compõem aquela sociedade em questão e se constituem na principal estrutura de poder que, em cada momento da história, assume posição hegemônica e direciona política e ideologicamente o processo de desenvolvimento. Os acordos ou ajustes provenientes da concertação entre os diferentes representantes do bloco socioterritorial são os pactos socioterritoriais que são determinantes para os projetos e ações de desenvolvimento futuro, ou seja, o pacto é o projeto político de desenvolvimento (DALLABRIDA, 2011; FUINI, 2015).

Com essas características a governança territorial engloba o Estado em todas as suas dimensões (municipal, estadual e federal) colocando em debate as suas relações com a sociedade civil e o setor privado (mercado). Essas três instâncias de acordo com Muls (2008) são as instituições locais, entendidas como "todos os organismos, associações, representações de classe, sindicatos e órgãos públicos que existem em um território e cujas ações são voltadas para a defesa e a promoção dos interesses de um determinado grupo social ou de uma parcela de sua população" (MULS, 2008, p. 17). Trata-se de um resultado da organização e das estratégias visando solucionar problemas específicos, ancorados no território. Não se trata de um ambiente organizacional amistoso, pois a própria existência de um espaço de negociação entre atores de diferentes segmentos evidencia antagonismos e conflitos intra e extra-classes.

A governança, por seu aspecto particular, acaba sendo um tipo de recurso específico e por essa natureza, é incomensurável, intransferível e não quantificável (BENKO, PECQUEUR, 2001). Essa discussão sobre recursos especificos situal a governança no rol dos fatores concorrenciais espaciais, ou novos fatores de localização, indentificados pela literatura geográfica-econômica vinculada a escola institucioanlista (Benko, 1996; Benko e Pecqueur, 2001; Storper, 1993; Scott, 2005; 
Selingardi-Sampaio, 2009). Além disso, uma importante consideração em relação às estratégias de governança está em sua essencia ou caráter, que pode ser privada, privada-coletiva, estatal-privada e pública e pública-tripartite (PIRES et al, 2017). Essa compreensão é relevante, pois busca considerar a importância da noção de governança territorial enquanto forma de organização do território em prol do desenvolvimento enfatizando a complexidade apresentada pela própria formação socioespacial.

Com isso, fica evidente a importância que os atores sociais têm na tomada de decisões e na representatividade nesse ambiente organizacional instituído, o que torna a existência um elemento essencial para um adequado processo de desenvolvimento territorial. Por fim, o desenvolvimento territorial deve ser entendido como um processo de mudança social de caráter endógeno, capaz de produzir solidariedade e cidadania (participação social e democrática), e que possa conduzir de forma integrada e permanente a mudança qualitativa e a melhoria do bem-estar da população de uma localidade ou uma região. Nas estratégias competitivas da globalização, o desenvolvimento territorial é dinamizado por expectativas dos agentes econômicos nas vantagens locacionais, no qual o território é o ator principal do desenvolvimento econômico regional, e as políticas, as organizações e a governança são recursos específicos, a um só tempo disponível ou a ser criado; quando disponível, tratar-se-ia de sua difusão no território, quando ausente, de sua criação. Desta forma, o desenvolvimento territorial é o resultado de uma ação coletiva intencional de caráter local, um modo de regulação territorial, portanto, uma ação associada a uma cultura, a um plano e instituições locais, tendo em vista arranjos de regulação das práticas sociais (PIRES et al, 2006, p.448).

\section{Os questionamentos ao desenvolvimento territorial: breves apontamentos e possíveis esclarecimentos}

A teoria do desenvolvimento territorial não está isenta de críticas. Dentre os seus principais questionadores se destacam os BRANDÃO (2002) e VAINER (2002 e 2007). Para eles, a teoria do desenvolvimento territorial seria a detentora de um discurso endógeno exagerado que, além de potencializar a fragmentação do território, descarta a importância do Estado nacional em suas responsabilidades de mediar e liderar a cooperação entre os entes federados? (BRANDÃO, 2002; VAINER, 2002, 2007). Continuando, em um ensaio, Brandão (2002) questiona se o local tem de fato a capacidade de planejar o processo de desenvolvimento. Para ele, essa teoria (1) compõe um pensamento único disseminador do discurso do fim das escalas intermediárias entre o local e o global; (2) debilita os centros nacionais de decisão e comando sobre o espaço nacional resididos no Estado central; (3) desconsidera o conflito social e a existência das classes sociais e; (4) preconiza a superação do Estado pelo mercado, bem como o fim da ação pública e a "vitória" da iniciativa privada e das parcerias.

Primeiramente, diferentemente do que apontam os seus críticos é preciso considerar a existência de novas estratégias de desenvolvimento e que elas são possíveis, principalmente na importância que elas demonstram em relação a construção de novos arranjos territoriais e que podem resultar em ganhos econômicos, geração de emprego e renda, melhoria da qualidade de vida e na possibilidade de espaços ou canais de participação e exercício da cidadania. As estratégias de desenvolvimento "de baixo para cima", ou local, possuem um caráter mais difuso e são sustentadas por fatores não apenas econômicos, mas também sociais, culturais e territoriais (LLORENS, 2001).

Nesse sentido, o apoio político-administrativo originado dos gestores públicos locais, além da conviç̧ão do papel a desempenhar no fomento econômico do território, são fatores fundamentais para as iniciativas de desenvolvimento local. Nessa perspectiva, o local, entendido como articulador de estratégias buscando promover políticas internas de desenvolvimento, não desqualifica a importância do Estado (em suas diferentes esferas) ou de outras instâncias federativas no planejamento do desenvolvimento. Elas continuam a ter a sua importância, mas com uma melhor participação das localidades, tendo com isso um ganho qualitativo nas políticas empregadas.

Para0nde!?, Porto Alegre, v.11, n.1, p.75-82, 2019. http://seer.ufrgs.br/paraonde

Edição Especial: “Geografia e transformações socioespaciais: dinâmicas agrárias e políticas do desenvolvimento regional” 
Além disso, Llorens (2001) esclarece que, não é o desmantelamento do Estado que nos levará ao desenvolvimento, mas sim a definição de uma "nova agenda" de ações articuladas com o setor empresarial e o conjunto da sociedade civil territorial. Dessa forma, a depender da política a ser desenvolvida é importante à articulação entre diferentes instâncias públicas, buscando ações coerentes tendo aí a importância da descentralização político-administrativa (territorial). A delegação de competências reais e a distribuição do poder que perpassa a descentralização políticoterritorial constituírem um requisito central para dotar os territórios da autonomia e liberdade necessárias para as estratégias de desenvolvimento local. Além disso, é sabido que num país cujo sistema de organização territorial é o federalismo, como o Brasil, cada ente federado possui as suas atribuições muito bem definidas pela carta constitucional, logo, longe de debilitar o Estado, o processo de desenvolvimento territorial pode resultar em seu fortalecimento ao reforçar sua própria base social e econômica.

A questão sobre o que pode o poder local, requer responder outro questionamento: o que é esse local? Se tomarmos o território como um elemento básico para compreender as novas possibilidades de se planejar o desenvolvimento, logo temos uma problemática em apontar os "limites" desse espaço. 0 local pode ser um município, um conjunto de municípios, um estado ou mesmo uma região (VITTE, 2007). A questão levantada é potencialidade de se efetivar processos de mobilização entre atores, instituições e recursos em prol do desenvolvimento. A própria ideia de local tem sido substituída pela literatura que trata da problemática do desenvolvimento "de baixo para cima", como por exemplo, Pecqueur (2005) e Pires (2015), para territorial. Essa mudança é um esforço na busca de afastar a adjetivo "localista" aos defensores do desenvolvimento endógeno. Além disso, a substituição de local para territorial busca enfatizar a multiplicidade das escalas que podem ser trabalhadas por essa perspectiva. Nesse sentido a consideração de Pires (2015, p.134) é importante, pois chama a atenção para o processo de recomposição espacial das ações humanas no capitalismo contemporâneo "que coloca em foco novas escalas hierárquicas na diversidade de analises do território (global, bloco regional multinações, nacional, a local e a regional)". Segundo o autor essa recomposição espacial das ações humanas que muito dialoga com a ideia construída por Benko (2001) ao analisar a nova reestruturação das escalas espaciais no capitalismo pós-fordista.

A importância do Estado brasileiro na amenização das desigualdades regionais é inconteste, sobretudo, no que tange a União e ao aparato político-institucional e financeiro. Dito isso, não podemos deixar de fazer uma observação sobre a própria forma de organização do Estado brasileiro que, apesar do processo de descentralização político-administrativa definido pela Constituição de 1988, mantem um ordenamento politico-territorial centralizador. Este aspecto é um dos principais limitadores do poder da sociedade organizada territorialmente, pois amputa as possibilidades de uma atuação mais ativa dessa sociedade. Logo, pensar em uma revisão no modelo federativo e buscar uma redistribuição tributário-financeira entre os entes federados, acaba sendo uma demanda importante. A questão federativo constitui um dos pilares que sustentam o problema do desenvolvimento brasileiro, ao lado da questão democrática e da questão socieconômica.

\section{Algumas experiências de governança territorial no estado de São Paulo}

No Brasil, são identificadas diferentes experiências de desenvolvimento territorializado, sobretudo, com estruturas de governança com graus diferenciados de institucionalização e consolidação. Essas experiências podem ser observadas nos diversos setores da economia, seja agrário (Câmaras Setoriais do Agronegócio) e industrial (APLs), inclusive aqueles com uma dimensão social, econômica e ambiental em sua estrutura, como os Comitês de Bácias Hidrográficas (CBHs).

Os APLs são aglomerações territoriais de agentes econômicos, políticos e sociais - com foco em um conjunto específico de atividades econômicas - que apresentam vínculos mesmo que incipientes. No país podemos encontrar diferentes definições de APLs, sejam aquelas elaboradas pelas entidades públicas, privadas ou instituições que agregam agentes públicos e privadas em projetos e políticas de

Para0nde!?, Porto Alegre, v.11, n.1, p.75-82, 2019. http://seer.ufrgs.br/paraonde

Edição Especial: “Geografia e transformações socioespaciais: dinâmicas agrárias e políticas do desenvolvimento regional” 
desenvolvimento dos arranjos. A definição básica de APL o caracteriza enquanto aglomerações de empresas localizadas em um mesmo contexto territorial, apresentando especialização produtiva, vínculos de interação, articulação e cooperação entre si e com outros atores locais, como governo municipal, além de outras instâncias (estadual e federal), associações empresariais, instituições de crédito, universidades e outros centros de pesquisa e desenvolvimento (FUINI, 2015).

As Câmaras Setoriais do Agronegócio são agrupamentos de representantes dos organismos, órgãos e entidades, públicas e privadas, que compõem os elos de uma cadeia produtiva do agronegócio, que tem por substrato um ou mais produtos. Tratam dos setores produtivos da Agropecuária, tendo sempre um enfoque sistêmico (Visão de Cadeia Produtiva). As Câmaras. segundo o Ministério da Agricultura, Pecuária e Abastecimento (MAPA), são importantes fóruns de discussão entre os diversos elos das cadeias produtivas, reunindo entidades representativas de produtores, empresários, instituições bancárias e de outros parceiros no setor, além de representantes de órgãos públicos e de técnicos governamentais (MAPA, 2017).

Por fim, os Comitês de Bacias Hidrográficas são organismos colegiados que fazem parte do Sistema Nacional de Gerenciamento de Recursos Hídricos (ANA). Devem ser entendidos enquanto instâncias públicas, com a finalidade de elaborar políticas para o uso dos recursos hídricos, bem como servir de colegiado para a resolução de conflitos sobre o uso da água (PIRES et al, 2011; PIRES et al, 2013; FUINI, 2015; RIBEIRO, TOPPAN; 2015).

Importante salientar que algumas dessas modalidades são iniciativas encontradas em todo o território nacional, porém com diferentes especificidades, dadas as legislações estaduais e municipais, como por exemplo, os APLs, as Câmaras e os Comitês de Bacias Hidrográficas. Devemos também considerar a existência de outras governanças e que não foram trabalhadas aqui e que são iniciativas estaduais, como os Conselhos Regionais de Desenvolvimento (Coredes) no Rio Grande do Sul (DALLABRIDA, 2011). Um aspecto comum a todas essas modalidades é o protagonismo do poder público, seja na esfera federal ou municipal, na manutenção do ambiente organizacional necessário para o desenvolvimento, apesar das distintas intensidades de atuação que podem ser observadas.

\section{Considerações Finais}

Esse trabalho teve como objetivo expor alguns aspectos que permeiam a discussão sobre o desenvolvimento local, buscando sanar algumas dúvidas sobre a temática e por fim indicar algumas experiências nacionais como possiblidades de estudos futuros. A relevância de um trabalho como o apresentado se assenta na atualidade do debate sobre o desenvolvimento e que longe de manter o foco na dualidade Estado x mercado (o que pode ser considerado como uma falsa polêmica, tendo em vista a forte dependência do agentes financeiros do aparato estatal), podemos pensar em novas possibilidades, como o desenvolvimento territorial. Isso não significa o rompimento no modo de produção, tampouco o descarte do papel do Estado no desenvolvimento.

A novidade esta no papel atribuído a sociedade civil, mesmo que esta seja marcada por entraves históricos, como muito bem podemos observar com a realidade brasileira. Mas, deixando o pessimismo de lado, tal perspectiva tem de ser tomada como um mecanismo de superação desses entraves à medida que buscamos um desenvolvimento no qual um dos seus objetivos enquanto processo é a construção de uma sociedade participativa e democrática. Nesse propósito a atuação do poder público é fundamental para mediar os conflitos, mas, não evitando centralizar o processo de decisório.

Não desqualificando a importância do Estado ou de outras instâncias federativas no planejamento do desenvolvimento, pois elas continuam a ter o seu papel e importância, o desenvolvimento local visa uma melhor participação das localidades, tendo com isso um ganho qualitativo nas políticas empregadas. Como afirmado anteriormente, não é o desmantelamento do Estado que nos levará ao desenvolvimento, mas sim a definição de uma "nova agenda" de ações articuladas com o setor

ParaOnde!?, Porto Alegre, v.11, n.1, p.75-82, 2019. http://seer.ufrgs.br/paraonde

Edição Especial: “Geografia e transformações socioespaciais: dinâmicas agrárias e políticas do desenvolvimento regional” 
empresarial e o conjunto da sociedade civil territorial. Nesse ambiente o papel dos diferentes organismos, associações, representações de classe, sindicatos e órgãos públicos que existem em um território são essenciais e devem ser um dos principais pontos de problematização daqueles que estão preocupados com a temática do desenvolvimento local, territorial ou endógeno.

Por fim, os exemplos citados ao final são experiências encontradas em diferentes estados da federação com características distintas e podem e devem ser objeto de pesquisas, uma vez que, podem representar casos de sucesso ou de debilidades devido às condições territoriais no quais estão inseridos. Concluímos esse breve trabalho afirmando que o fato de haver problemas naquilo que definimos como experiência de desenvolvimento local não descarta a teoria enquanto possibilidade de compreender fatos estilizados no que toca as novas estratégias dos atores públicos e privados no processo de elaboração, execução e, claro, avaliação do processo de desenvolvimento. É preciso se debruçar sobre essas experiências buscando os aspectos que a sustentam, os atores que a compõem, os impactos que são gerados no território e o que isso representa para a dinâmica territorial em sua complexidade.

\section{Referências}

BENKO, G. A recomposição dos espaços. In.: Interações - Revista Internacional de Desenvolvimento Local. Universidade Católica Dom Bosco/MS, vol. 1, n. 2, p. 7-12, mar. 2001.

BENKO, G.; PECQUEUR, B. Os recursos de territórios e os territórios de recursos. Geosul - Revista do Departamento de Geociências, Florianópolis, v. 16, n. 32, p. 31-50, jul./dez, 2001.

PECQUEUR, B. O Desenvolvimento Territorial: uma nova abordagem dos processos de desenvolvimento para as economias do Sul. Raízes, Campina Grande, vol. 24, no 1 e 2, jan./dez. 2005.

BOYER, R. Estado, mercado e desenvolvimento: uma nova síntese para o século XXI. In.: Economia e Sociedade. Campinas, n.12. Jun. 1999.

BRANDÃO, C. Processo de industrialização e disparidades inter-regionais no Brasil: a necessidade do diálogo entre as politicas industriais e as politicas regionais. In.: TONI, J. Dez anos de Política Industrial: Balanço e perspectivas. Brasília: ABDI, 2015.

BRANDÃO, C. Localismos, mitologias e banalizações na discussão do processo de desenvolvimento. Anais do VII Encontro Nacional de Economia Política e II Colóquio Latino Americano de Economistas Políticos. Curitiba, 2002.

COSTA, E.J.M. Arranjos Produtivos Locais, Políticas Públicas e Desenvolvimento Regional. 1. ed. Brasília: Mais Gráfica, 2010. v. 1.404p.

DALLABRIDA, V.R. Governança territorial e desenvolvimento: descentralização politicoadministrativa, estruturas subnacionais de gestão do desenvolvimento e capacidades estatais. Rio de Janeiro: Garamond, 2011.

DALLABRIDA, V.R. GOVERNANÇA TERRITORIAL E DESENVOLVIMENTO: as experiências de descentralização político-administrativa no Brasil como exemplos de institucionalização de novas escalas territoriais de governança. In: Anais do I Circuito de Debates Acadêmicos - II CODE. Brasília: IPEA, 2011.

LLORENS, F.A. Desenvolvimento Econômico Local - Caminhos e Desafios para a Construção de uma Nova Agenda Política. Rio de Janeiro: BNDES. 2001.

MAPA (Ministério da Agricultura, Pecuária e Abastecimento). As Câmaras Setoriais e Temáticas do MAPA. Disponível em: http://www.agricultura.gov.br/assuntos/camaras-setoriaistematicas/camaras-setoriais-e-tematias-do-mapa. Acessado em: 10 Dez 2017.

ParaOnde!?, Porto Alegre, v.11, n.1, p.75-82, 2019. http://seer.ufrgs.br/paraonde

Edição Especial: “Geografia e transformações socioespaciais: dinâmicas agrárias e políticas do desenvolvimento regional” 
MULS, L.M. Desenvolvimento Local, Espaço e Território: o conceito de capital social e a importância da formação de redes entre organismos e instituições locais. Economia (Brasília), v. 9, p. 1-21, 2008.

PIRES, E.L.S et al. A Governança Territorial Revisitada: dispositivos institucionais, noções intermediárias e níveis de regulação. In.: Geographia, Niterói, vol. 19, n. 41, 2017.

PIRES, E.L.S. A recomposição das escalas de governança, Estado e desenvolvimento territorial no Brasil. In.: GeoTextos, vol. 11, n. 1, julho 2015.

PIRES, E. (coord.); FIGUEIREDO FILHO, W.B.; FUINI, L.L.; MANCINI, R.F.; OTANI, M; SOUZA, M.C.; STAUD, N.; VERDI, A.R. As modalidades de governança territorial no Estado de Estado de São Paulo: relatório de pesquisa. Rio Claro: UNESP, 2013.16 p.

PIRES, E. L. S. et al. Governança Territorial: Conceitos, Fatos e Modalidades. Rio Claro: Editora da Pósgraduação em Geografia/ IGCE/ UNESP, 2011.

PIRES, E; MÜLLER, G; VERDI, A. Instituições, territórios e desenvolvimento local: delineamento preliminar dos aspectos teóricos e morfológicos. Geografia, Rio Claro, v. 31, p. 437-454, set./dez, 2006.

RIBEIRO, J. R.; TOPPAN, R.N. Território e Governança: as principais contribuições da Geografia para pensar o Desenvolvimento. Revista UNIARA, v. 18, p. 29/15-43, 2015.

SANTOS, M. A revanche do território. In SANTOS, M. O País distorcido: o Brasil, a globalização e a cidadania. São Paulo. PubliFolha, 2002.

SANTOS, M. O retorno do território. In. SANTOS, M; SOUZA, M.A; SILVEIRA, M.L. Território, globalização e fragmentação. São Paulo: Ed. Hucitec, 1994.

SANTOS, M. Sociedade e Espaço: a Formação Social como Teoria e como Método. In.: Boletim Paulista de Geografia, n. 54, São Paulo: AGB-SP, 1977.

SCOTT, A.J. Les moteurs régionaux del'économie mondiale. In. : Revue Géographie, économie, societé, v.7, p.231-253, 2005.

STORPER, M. Territorialização numa economia global: potencialidades de desenvolvimento tecnológico, comercial e regional em economias subdesenvolvidas. In: LAVINAS, L.; CARLEIAL, L. M.; NABUCO, M. R. (Orgs.). Integração, região e regionalismo. São Paulo: Bertrand Brasil, 1993.

VAINER, C. B.. Planejamento Territorial e Projeto Nacional: os desafios da fragmentação. In.: Revista Brasileira de Estudos Urbanos e Regionais (ANPUR), v. 9, p. 09-23, 2007.

VAINER, C. B.. As escalas do poder e o poder das escalas: o que pode o poder local?. In.: Cadernos IPPUR/UFRJ, 2002.

VITTE, C. C. S. Experiências de políticas de desenvolvimento econômico local nos municípios da Região Metropolitana de Campinas (SP) e os impactos no território. Scripta Nova (Barcelona), v. XI, p. 01-15, 2007. 